\title{
Host Plant Specialization and Species Turnover of Caterpillars Among Hosts in the Brazilian Cerrado
}

\author{
Helena C. Morais ${ }^{1}$, Edison R. Sujii ${ }^{2}$, Mario Almeida-Neto ${ }^{1}$, Plauto S. De-Carvalho ${ }^{3}$, John D. Hay ${ }^{1}$, and Ivone R. Diniz ${ }^{4,5}$ \\ ${ }^{1}$ Departamento de Ecologia, Instituto de Ciências Biológicas, Universidade de Brasília, CEP 70.910-900, Brasília, DF, Brazil \\ ${ }^{2}$ Embrapa Cenargen, Brasília, DF, Brazil \\ ${ }^{3}$ Programa de Pós Graduação em Ecologia, Instituto de Ciências Biológicas, Universidade de Brasília, Brasília, DF, Brazil \\ ${ }^{4}$ Departamento de Zoologia, Instituto de Ciências Biológicas, Universidade de Brasília, Brasília, DF, Brazil
}

\begin{abstract}
Decrease in the species composition similarity of herbivore assemblages with increasing phylogenetic distance between host plants is a widespread pattern. Here we used data for caterpillars in the Brazilian Cerrado to investigate how the similarity in caterpillar species composition decreases as the taxonomic level and genetic distance (GD) of their host plants increases. In addition, we elucidate the plant taxonomic level that provides the greatest contribution to turnover in the caterpillar species composition among host taxa. Adult Lepidoptera were reared from caterpillars collected from 52 plants over 13 yr in the same area, with each host plant sampled for $1 \mathrm{yr}$. Most species were specialists, with 66 percent of genus specialists among the nonsingleton species. The similarity in caterpillar species composition across plant taxa decreased from host species to genera, and from host genera to orders. Above this level, the similarity was consistently low. The GD between plants explained 82 percent of the variation in the similarity of caterpillar species composition. The contribution of caterpillar species turnover among host orders from the same superorder and among host superorders from the same subclass explained 70 percent of the caterpillar species richness as a whole. Our results lend support to the view that most tropical caterpillars are host specialists. Our findings further indicate that the number of orders and superorders of plants provide the greatest contribution to the total caterpillar richness compared with all of the other host taxonomic levels combined.
\end{abstract}

Key words: additive partitioning of $\beta$ diversity; genetic distance; Lepidoptera; plant taxonomic distance.

INTERACTIONS INVOLVING HERBIVOROUS INSECTS AND THEIR HOST PLANTS comprise one of the richest components of most terrestrial food webs (Jaenike 1990, Godfray et al. 1999, Price 2002). Hence, understanding the interaction patterns between plants and their herbivorous insects is an important step toward obtaining a better general comprehension of the processes that regulate interaction networks. One of the oldest generalizations concerning food webs that are applicable to plant-herbivore networks is that specialized interactions are not randomly established (Cattin et al. 2004).

The feeding specialization of herbivorous insects ranges from monophagy (i.e., extreme specialists) to polyphagy (i.e., broad generalists). Despite such variation, it has been widely reported that most herbivorous insect species feed on a small fraction of phylogenetically related plant species that are available in local floras (Strong et al. 1984, Jaenike 1990, Futuyma \& Mitter 1996). Phylogenetically related plants also tend to harbor similar species compositions of herbivore insects (Ødegaard 2000, Jermy \& Szentesi 2003, Irschick et al. 2005, Weiblen et al. 2006, Dyer et al. 2007). Because host phylogeny has not been fully resolved, several authors have used the taxonomic relatedness of plants as a surrogate in studies investigating the evolution of feeding specialization in herbivore insects (Futuyma \& Mitter 1996, Ødegaard et al. 2005).

Although there is a broad consensus concerning some aggregate patterns involving plant-insect interactions (Strong et al. 1984,

Received 29 March 2010; revision accepted 23 September 2010.

${ }^{5}$ Corresponding author; e-mail: irdiniz@unb.br

(C) 2011 The Author(s)

Journal compilation (C) 2011 by The Association for Tropical Biology and Conservation
Lewinsohn et al. 2005), several gaps in the quantitative aspects of these patterns remain. For instance, it is unclear whether the species composition similarity among herbivore assemblages decreases gradually or sharply with the phylogenetic distance of their host plants (Futuyma \& Mitter 1996, Lewinsohn et al. 2005). Ødegaard et al. (2005) investigated this question for phytophagous beetles in Panama by minimizing the undesirable influence of the variation in plant species composition on the degree of feeding specialization of the herbivores (e.g., Novotny et al. 2006). They found that similarity dropped at decreasing rates from species to genus, to family, and to order, which indicated that the most recent taxonomic branching events were most important for host utilization among those insects.

In the present study, we focused on local interactions between folivorous caterpillars (Lepidoptera) and their host plants in the Brazilian Cerrado to investigate how the degree of similarity in the species composition of caterpillars among different host plant species is affected by the plant taxonomic distance (TD). This Neotropical biome is considered a global biodiversity hotspot that harbors approximately 11,600 vascular plant species, among which about 44 percent are endemic (Furley 1999, Klink \& Machado 2005, Sano et al. 2008). The cerrado entomofauna is also believed to have very high species richness (Becker 1991, Brown \& Gifford 2002). The total richness of Lepidoptera is estimated to comprise 9000 species (Becker 1991), which represent nearly 11 percent of the Neotropical Lepidoptera richness (Diniz \& Morais 1997).

Our study system consisted of field collection and a laboratory rearing program for immature Lepidoptera on their host plants that 
were sampled at a site in the core area of the Brazilian Cerrado (Diniz \& Morais 1997, Diniz et al. 2001). This data base was used as follows: (1) to investigate whether the similarity in caterpillar species composition gradually decreases with increasing taxonomic levels of their host plants or, alternatively, decreases sharply at one particular level; (2) to describe the relationship between host plant genetic distance (GD) and the similarity in caterpillar species composition; and (3) to elucidate the taxonomic levels at which differences in caterpillar species turnover among host taxa differ from the expected outcome according to a null model in which caterpillar individuals fed randomly on their host plants.

\section{METHODS}

STUDY SITE.-This study was conducted in the Fazenda Água Limpa $\left(15^{\circ} 30^{\prime} \mathrm{S}, 47^{\circ} 25^{\prime} \mathrm{W}\right)$, which is a 5000 -ha protected experimental station that is owned by the University of Brasilia in the Federal District of Brazil. The region is characterized by a distinct dry season from May to September during which $<7$ percent of the annual rainfall occurs; the mean annual rainfall is $1417 \mathrm{~mm}$, and the mean annual temperature is $22.3^{\circ} \mathrm{C}$ (based on continual records from 1980 to 2004; RECOR Meteorological Station, http://www.recor.org.br, located approximately $10 \mathrm{~km}$ from the study site). The local altitude ranges from 1048 to $1160 \mathrm{~m}$ asl. The experimental station contains different vegetation physiognomies with a predominance of cerrado sensu stricto, which is the focal habitat of our study. Further information about the Cerrado vegetation can be found in Oliveira-Filho and Ratter (2002), and details about the vegetation at the study site are described by Felfili et al. (2000).

STUDY SYSTEM.-We sampled caterpillars from 52 host plant species in 27 families and 16 orders (Table S1). These host plants include species from seven of the ten families with the greatest species richness in the Brazilian Cerrado (Sano et al. 2008). The sampled plant species are representative of this area and correspond to 76 percent of the importance value index (IVI = relative density + relative frequency + relative basal area) (Fonseca \& Silva 2004) and to 80 percent of the basal area (Felfili et al. 2000). The host species varied in size with a predominance of shrubs, which is characteristic of the cerrado sensu stricto.

SAMPLING METHODS.-Field sampling was conducted from 1993 to 2006. We sampled caterpillars weekly on 15-20 plant individuals up to a height of $2.5 \mathrm{~m}$ for each plant species for $1 \mathrm{yr}(N \cong 900$ individuals for each plant species). For each host individual, the foliage was carefully examined for at least $5 \mathrm{~min}$. The sampling program was designed to avoid a repeated collection on the same host individuals. All externally feeding caterpillars, including leaf rollers and leaf tiers, were collected from the foliage by hand and reared in clear plastic jars at an ambient temperature and humidity in the laboratory. Fresh leaves from the appropriate host plant were provided as needed. All of the data presented herein were based on adults that emerged in the laboratory. Voucher specimens were deposited in the Entomological Collection of the Zoology Department of the University of Brasilia.
Plant Relatedness.-To examine the decrease in similarity in the caterpillar species composition with an increased TD of their host plants, we used an approach similar to that described by Ødegaard et al. (2005) for phytophagous beetles in Panama. First, we grouped the host plant species into different taxonomic levels according to the Angiosperm Phylogeny Website (Stevens 2008). Subsequently, we calculated the degree of species composition similarity among the caterpillar assemblages within distinct host taxonomic levels using the Bray-Curtis (BC) and Sørensen similarity indices (Magurran 2004). The species composition similarity of the caterpillar assemblages among conspecific hosts was denoted as Distance 1. According to the same approach, we used the following nomenclature: the species similarity of the caterpillar assemblages among species within genus was designated as Distance 2; genera within family as Distance 3; families within order as Distance 4; orders within superorder as Distance 5; superorders within subclass as Distance 6; and subclasses within class as Distance 7. In the case of Distance 1, we used samples from intercalated dates spanning $1 \mathrm{yr}$ because our data did not permit a comparison of the caterpillar fauna between host individuals. Note that Distance 1 differs from the evolutionary context of comparisons between host species and higher taxonomic levels. Following the approach of Ødegaard et al. (2005), we tested magnoliids at the subclass level (Distance 6). We did not use the solution provided by Ødegaard et al. (2005) for the covariance problem because in our approach, the similarity in caterpillar species composition within each taxonomic level was calculated by pooling all caterpillar species collected for each host taxa.

GD BETWEEN HOST PLANTS.- The sequences of the chloroplast ribulose-1,5-bisphosphate carboxylase gene ( $\mathrm{rbcL}$ ) were downloaded from GenBank (see accession numbers in Table S2) and aligned using MEGA4 software (Tamura et al. 2007). The data set comprised 37 sequences of $1180 \mathrm{bp}$. We estimated the pairwise GD from the evolutionary divergence between sequences by maximum composite likelihood method (confidence was assessed by 1000 bootstrap replicates) using MEGA4 software (Tamura et al. 2004, 2007). The included codon positions were as follows: $1 s t+2 n d+3 r d+$ noncoding. All of the positions with gaps and missing data were eliminated from the data set (complete deletion option). Following the criteria proposed by Ødegaard et al. (2005), closely related species or related genera were used to determine the phylogenetic relationships of plant species that lacked DNA sequences (Table S2).

DATA ANALYSIS.-For each taxonomic level, the similarity in caterpillar species composition among plant taxa was calculated using the BC and Sørensen similarity indices (Magurran 2004). A generalized linear model (McCullagh \& Nelder 1989) in which the binomial distribution was attributed to the dependent variable was used to test differences in the similarity in caterpillar species composition among plant taxonomic levels. To adjust for any super dispersion of the data due to an excess of zeros, the quasi-likelihood method was used to estimate the heterogeneity factor that was incorporated into the variance function. The breaking point for the segmented regression model was also calculated to estimate the taxonomic level of the plants after which the dependent variable did 
not demonstrate a significant variation. This model fits the average similarity index of the caterpillar species composition from the lowest to the highest host plant taxa as a continuous function. The model provides an improvement of the approach used by Ødegaard et al. (2005), in which the mean similarities of beetles were compared between two consecutive taxonomic levels using $t$-tests. To examine whether the similarity in caterpillar species composition varied with the host plant GD, we used a logarithmic regression as described by Ødegaard et al. (2005) and Novotny et al. (2006), in which each point corresponded to a species pair.

The above-described analyses focused on the shape of the relationship between the similarity in caterpillar species composition and plant relatedness. Another important feature of our study was the determination of the plant taxonomic level at which differences in the caterpillar species composition among hosts (turnover) differed from a null expectation based on the random use of plants by caterpillars. To address this issue, we used the additive partitioning of $\beta$ diversity proposed by Crist $e$ al. (2003). This approach was originally developed for a hierarchical sampling design, but it can also be used to measure the partitioning of diversity between two noninclusive species sets (e.g., hosts/parasites, plants/herbivores). Here we used an unrestricted individual-based randomization algorithm in which the probability of an individual caterpillar being found on a given host species is equal to the relative abundance of caterpillars on that specific host. This weighting procedure was used because the number of plant species was distributed unequally among plant taxa at the same taxonomic level.

The species similarities and additive partitioning of $\beta$ diversity were calculated using EstimateS 8.0 (Colwell 2008) and PARTITION 3.0 (Veech \& Crist 2009), respectively. All other statistical analyses were performed using $\mathrm{R}$ language ( $\mathrm{R}$ Development Core Team 2006).

\section{RESULTS}

We obtained 2827 adult Lepidoptera belonging to 377 species and 39 families. The four richest families (Elachistidae, Gelechiidae, Geometridae, and Pyralidae) represented 47 percent of the species and 53 percent of the individuals. Most of the caterpillar species $(N=253)$ were found on only one host species, of which almost half $(N=119)$ of these were singletons. Only 72 species of Lepidoptera (19\%) were detected on two or more plant families and 59 species (16\%) on two or more host species from different orders, of which 35 fed on plant species from two or more superorders, and seven fed on plants from different subclasses. Excluding singleton species, only $88(34 \%)$ of the caterpillar species were found on two or more host genera, and 70 percent were plant family specialists.

A strong decrease was observed in the degree of similarity in caterpillar species composition from different conspecific hosts to different confamilial genera (Fig. 1). The segmented regression model demonstrated a mean decrease of 35.8 percent in the degree of similarity in caterpillar species composition (BC) between contiguous host taxonomic levels $(t=9.307, P<0.001)$. The estimated breaking point for the segmented regression model was $4.98 \pm 0.0002$ (mean $\pm \mathrm{SE}$ ), indicating that the similarity in

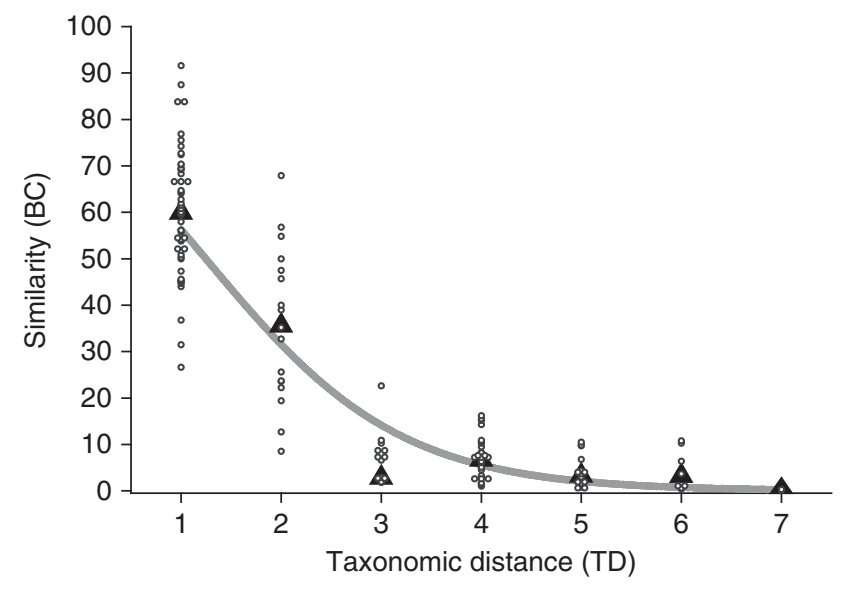

FIGURE 1. Relationship between the Bray-Curtis (BC) similarities of caterpillar assemblages for each taxonomic level of host plants vs. the taxonomic distance (TD) between host plants in the Brazilian Cerrado. Expected values for the function $\mathrm{BC}=\exp (1.2818-1.028 \times \mathrm{TD}) /(1-\exp (1.2818-1.028 \times \mathrm{TD})$.

caterpillar species composition did not change significantly after Distance 5 (host orders within superorders) (Fig. 1). The model $\mathrm{BC}=\exp (1.028 \times \mathrm{TD})$ fits the observed data $\left(R^{2}=0.935\right.$, $P=0.012)$. The same pattern was observed for the Sørensen coefficient of similarity with a slightly smaller value of $R^{2}=0.89$.

The BC similarity in caterpillar species composition decreased with an increased GD between the host plants (Fig. 2). Plant relatedness explained 82 percent of the variation in the similarity in caterpillar species composition between pairs of host species $\left(\mathrm{BC}=18.945-19.91 \log [\mathrm{GD}] ; \quad t=68.8, \quad \mathrm{df}=1033, \quad R^{2}=0.82\right.$, $P<0.001)$. Consistent with the results of the plant taxonomic analysis, we found the same decreasing pattern using Sørensen's similarity index $\left(R^{2}=0.58\right)$.

The caterpillar species turnover among host taxa differed significantly from the random expectation for all plant taxonomic

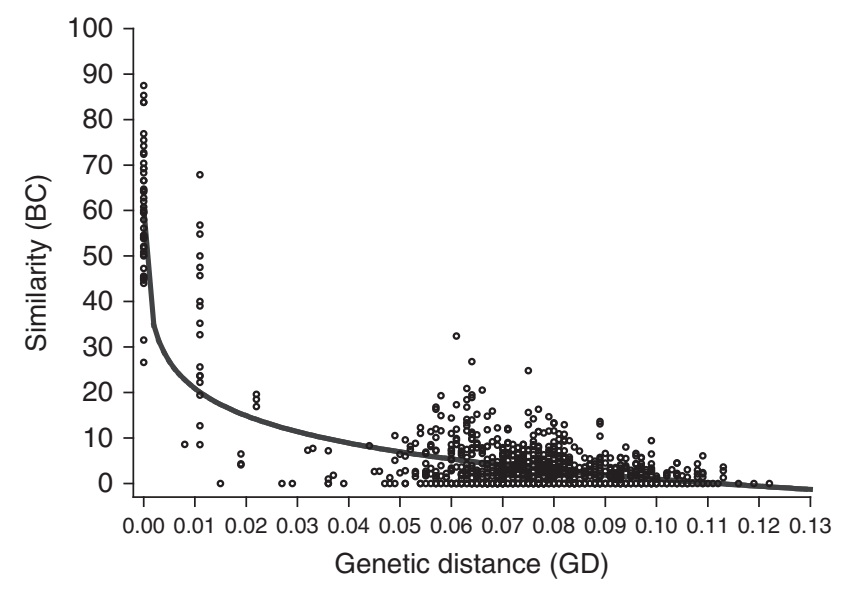

FIGURE 2. Relationship between the Bray-Curtis (BC) similarity of caterpillar assemblages on host plants vs. the genetic distance (GD) between host plants for all pairwise combinations of plants in the Cerrado. 


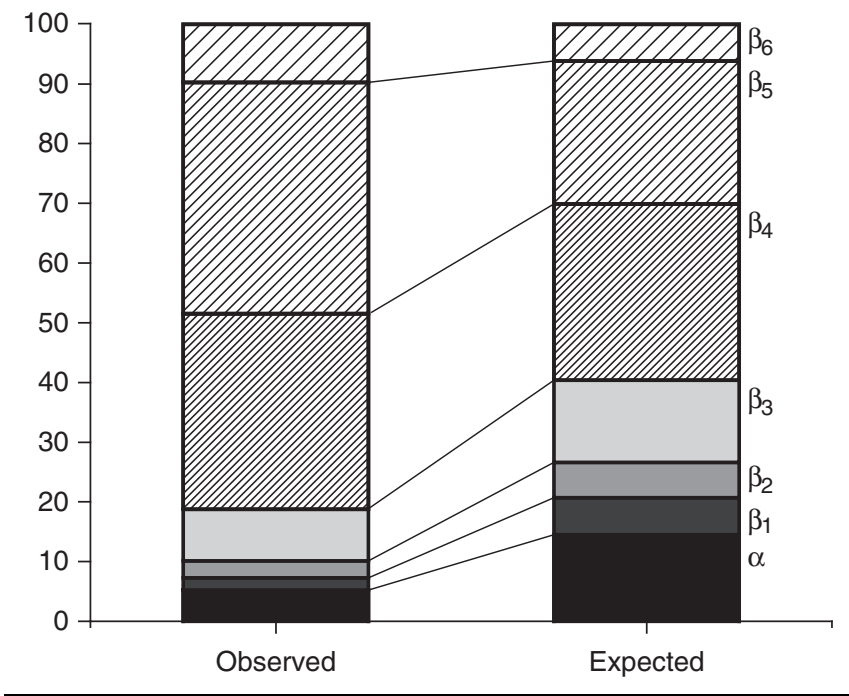

FIGURE 3. Additive partition of caterpillar species richness across six plant taxonomic levels. Values are expressed as the percent of the total richness of caterpillars explained by each taxonomic level. The observed partitions were compared with the expected values from the individual-based randomization $(\mathrm{H} 1)$. $\alpha$, within host species; $\beta_{1}$, among species from the same genus; $\beta_{2}$, among genera from the same family; $\beta_{3}$, among families from the same order; $\beta_{4}$, among orders from the same superorder; $\beta_{5}$, among superorders from the same subclass; $\beta_{6}$, among subclasses of angiosperms.

levels according to the individual-based null model. The turnover in caterpillar species composition was lower than that expected based on the null model from different taxa within host species to genera within host families. Higher values were, however, obtained for the caterpillar species turnover from host families within a plant order to higher taxonomic levels (Fig. 3). The pooled contributions of species to the family level accounted for $<20$ percent of the total caterpillar richness. The total caterpillar richness was mostly explained by differences in the caterpillar species composition among orders $(32.7 \%)$ and superorders $(38.8 \%)$ of hosts.

\section{DISCUSSION}

The present study demonstrated that most caterpillar species feed on a small fraction of the host plant species on a local scale. Among the nonsingleton caterpillar species, only 34 percent were found on two or more host genera, and 70 percent were restricted to a single host family. These findings are similar to those previously reported for Lepidoptera in tropical regions. Janzen (2003) recorded that 61 percent of the Saturniidae in Costa Rica are host family specialists, and Barone (1998) found that 85 percent of the leaf-chewer species (mostly Lepidoptera) in Panama are family specialists (see also Novotny \& Basset 2005). In a study of caterpillars on trees in Papua New Guinea, Novotny et al. (2002a) showed that 77 percent of the species were family specialists, whereas 67 percent of species were genus specialists. In contrast, they found a lower percentage of monophagy $(11 \%)$ in comparison to the results obtained in the present study (51.9\% among the nonsingleton species). This differ- ence can be explained by the finding that half (21 out of 41$)$ of the sampled host genera were represented by only one species in our study area. Six host genera contained two or more species sampled for caterpillars, and ten of the remaining genera had congeners, which were rare in the study area.

Low intrageneric species richness at the local scale is particularly common among the Cerrado flora. This finding is similar to the results obtained by Novotny et al. (2004) in secondary rain forest vegetation in New Guinea and lends support to the hypothesis that the plant species composition plays an important role in the local degree of the feeding specialization of caterpillar species. Aside from this characteristic of the Cerrado flora, the caterpillar fauna in this vegetation is characterized by a high proportion of shelter building microlepidoptera. This results in an even more restricted relationship of the caterpillars with the host plants (e.g., Loeffler 1998, Novotny \& Basset 2005) and consequently a high degree of diet specificity.

Our results showing relatively narrow diet breadths for caterpillar species imply that the composition of caterpillar species is similar between closely related host species. The similarity in caterpillar species composition between plants decreased mainly from host species in the same genus to host families in the same order. Overall, this decrease in similarity was characterized by a steeper drop from conspecific host individuals to confamilial host genera and continued to decrease to host orders in the same superorder (i.e., Distance 5). Above this taxonomic level, the similarities in caterpillar species composition between host taxa of the same taxonomic group were consistently low. Ødegaard et al. (2005) found very similar results for phytophagous beetles in two lowland forest sites in Panama. They demonstrated a steeper decrease in the similarity of beetle species between congeneric or confamilial host species and small changes in similarity from families to subclasses. Therefore, Ødegaard et al.'s (2005) hypothesis that the most recent taxonomic branching events are the most important determinants of host utilization among phytophagous beetles is also supported by our data for caterpillars in the Brazilian Cerrado.

In contrast to results for beetle species in a Panamanian forest, the decrease in similarity in herbivore species composition with an increased GD between host species occurred at a faster rate for caterpillars in the Brazilian Cerrado. The slope of our log model was almost three times greater (7.4 and 19.9) than that obtained by Ødegaard et al. (2005), which indicates that the caterpillar fauna differs greatly even between genetically close host species. In addition, none of the plant-host species pairs with GD values $>0.8$ had similarities in the herbivore species composition (BC) above 20 percent in our data set, whereas Ødegaard et al. (2005) found similarity values between 20 percent and 40 percent for several host species pairs with GD values above 0.8 . We hypothesize that the lower similarity found in our study can be attributed to the higher specialization of Lepidoptera caterpillars compared with beetles (see Weiblen et al. 2006).

The structure of plant-herbivore relationships is often investigated by considering hosts as habitats (or sites) and their associated insect fauna as local assemblages (Frenzel \& Brandl 2001). In the present study, we used the additive partitioning of $\beta$ diversity (Crist 
et al. 2003) to evaluate the taxonomic levels that provide the greatest contribution to turnover in the caterpillar species composition among host taxa. We found that the turnover in caterpillar species composition was lower than what would be expected at random from the species to the family level and was significantly higher above the family level. The pooled contributions of species to the family level accounted for $<20$ percent of the total caterpillar richness. In fact, the total caterpillar richness was mostly explained by differences in caterpillar species composition among orders $(32.7 \%)$ and superorders $(38.8 \%)$ of hosts. These findings appear to be inconsistent with previous studies that demonstrated the presence of low herbivore similarity (or high turnover) among lower plant taxonomic levels (genus, family) in tropical regions (Frenzel $\&$ Brandl 2001, Novotny et al. 2002b, Dyer et al. 2007). This inconsistency is, however, due to the additive partitioning approach, which sorts the total herbivore species richness across several taxonomic levels, whereas the typical measures of species composition similarity do not account for the nested configuration of the taxonomic classification.

It is well-known that plant species richness explains a large part of the variation observed in herbivore richness across geographical gradients and spatial scales (see Lewinsohn \& Roslin 2008). Novotny et al. (2002a) found that most herbivore insects in a New Guinea rain forest are oligophagous and feed on several congeneric plant species. They suggested that there is a low spatial turnover in herbivore species composition among tropical sites due to the commonality of species-rich plant genera in that region (see also Novotny et al. 2007). Our results demonstrate a higher degree of monophagy compared with those documented for New Guinea and also indicate that a higher turnover of caterpillar species occurs from order to higher taxonomic levels of host plants. It will be important to determine whether this result can be confirmed in other host plant systems or whether it is a singular characteristic of this system in the Cerrado.

\section{ACKNOWLEDGMENTS}

We are especially grateful to Lee Dyer for providing valuable suggestions concerning our manuscript. We gratefully acknowledge the expertise of Vitor O. Becker, who identified the moth species, the field assistance of several students from the University of Brasilia in the data collection since 1993, and the logistical support of the University of Brasília. We thank Joseane Padilha da Silva for statistical advice. Financial support was provided by CNPq, FAPDF/ PRONEX, and the University of Brasília.

\section{SUPPORTING INFORMATION}

Additional Supporting Information may be found in the online version of this article:

TABLE S1. The plant species examined, classified according to APG (Stevens 2008).
TABLE S2. Correspondence of the sampled plant species in the Cerrado vegetation with those used for genetic distance.

Please note: Wiley-Blackwell is not responsible for the content or functionality of any supporting materials supplied by the authors. Any queries (other than missing material) should be directed to the corresponding author for the article.

\section{LITERATURE CITED}

BARONE, J. A. 1998. Host-specificity of folivorous insects in a moist tropical forest. J. Anim. Ecol. 67: 400-409.

BeCKer, V. O. 1991. Fauna de lepidópteros dos cerrados: composição e afinidades com as faunas das regióes vizinhas. In Resumos do I Encontro de Botânicos do Centro Oeste. Soc. Bras. Bot., Brasília, Brazil, p. 9.

BRown, K. S. JR., AND D. R. GuIfFord. 2002. Lepidoptera in the cerrado landscape and the conservation of vegetation, soil, and topographical mosaics. In P. S. Oliveira and R. J. Marquis (Eds.). The cerrados of Brazil, pp. 201-222. Columbia University Press, New York, New York.

Cattin, M. F., L. F. Bersier, C. Banasěk-Richter, R. Baltensperger, and J. P. GABRIEL. 2004. Phylogenetic constraints and adaptation explain foodweb structure. Nature 427: 835-839.

Colwell, R. K. 2008. EstimateS: Statistical estimation of species richness and shared species from samples. Version 8.0.0 User's Guide and Application. Available at http://viceroy.eeb.uconn.edu/estimates (accessed 15 September 2008).

Crist, T. O., J. A. Veech, J. C. Gering, and K. S. Summerville. 2003. Partitioning species diversity across landscapes and regions: A hierarchical analysis of $\alpha, \beta$, and $\gamma$ diversity. Am. Nat. 162: 734-743.

DinIZ, I. R., AND H. C. MoRAIs. 1997. Lepidopteran caterpillar fauna of cerrado host plants. Biodiversity Conserv. 6: 817-836.

Diniz, I. R., H. C. Morais, And A. J. A. Camargo. 2001. Host plants of Lepidopteran caterpillars in the Cerrado of the Distrito Federal. Revta. Brazil. Entomol. 45: 107-122.

Dyer, L. A., M. S. Singer, J. T. Lill, J. O. Stiremam, G. L. Gentry, R. J. MarQuis, R. E. Ricklefs, H. F. Greeney, D. L. Wagner, H. C. Morais, I. R. Diniz, T. A. Kursar, and P. D. Coley. 2007. Host specificity of Lepidoptera in tropical and temperate forests. Nature 448: 696-699.

Felfili, J. M., A. V. Rezende, M. C. Silva Junior, And A. Silva. 2000. Changes in the floristic composition of cerrado sensu stricto in Brazil over a nineyear period. J. Trop. Ecol. 16: 579-590.

Fonseca, M. S., And M. C. Silva JR. 2004. Fitossociologia e similaridade florística entre trechos de Cerrado sentido restrito em interflúvio e em vale no Jardim Botânico de Brasília, DF. Acta Bot. Bras. 18: 19-29.

Frenzel, M., AND R. BRANDl. 2001. Hosts as habitats: Faunal similarity of phytophagous insects between host plants. Ecol. Entomol. 26: 594-601.

FURLEY, P. A. 1999. The nature and diversity of Neotropical savanna vegetation with particular reference to the Brazilian Cerrados. Global Ecol. Biogeogr. 8: 223-241.

Futuyma, D. J., AND C. MitTer. 1996. Insect-plant interactions: The evolution of component communities. Philos. Trans. R. Soc. Lond. B 351: $1361-1366$.

Godfray, H. C., T. Lewis, and J. Memmott. 1999. Studying insect diversity in the tropics. Philos. Trans. R. Soc. Lond. B 354: 1811-1824.

Irschick, D., L. Dyer, ANd T. W. Sherry. 2005. Phylogenetic methodologies for studying specialization. Oikos 110: 404-408.

JAENIKE, J. 1990. Host specialization in phytophagous insects. Ann. Rev. Ecol. Syst. 21: 243-273.

JanZEN, D. H. 2003. How polyphagous are Costa Rican dry forest saturniid caterpillars? In Y. Basset, V. Novotny, S. E. Miller, and R. Kitching (Eds.). Arthropods of tropical forests: Spatio-temporal dynamics and resource use in the canopy, pp. 369-379. Cambridge University Press, Cambridge, UK. 
Jermy, T., AND A. Szentesi. 2003. Evolutionary aspects of host plant specialization-A study on bruchids (Coleoptera:Bruchidae). Oikos 101: 196-204.

Kuink, C. A., AND R. Machado. 2005. Conservation of the Brazilian Cerrado. Conserv. Biol. 19: 707-713.

LEWINSOHN, T. M., AND T. RosLIN. 2008. Four ways towards tropical herbivore mega diversity. Ecol. Lett. 11: 398-416.

Lewinsohn, T. M., V. Novotny, And Y. Basset. 2005. Insects on plants: Diversity of herbivore assemblages revisited. Ann. Rev. Ecol. Evol. Syst. 36: 597-620.

LoEfFler, C. C. 1998. Host plant and habitat effects on behavior, survival, and growth of early instar Dichomeris leuconotella (Lepidoptera:Gelechiidae), leaf-folders on goldenrods. J. Res. Lepid. 32: 53-74.

MagurRan, A. E. 2004. Measuring biological diversity. Blackwell Science, Oxford, UK.

McCullagh, P., And J. A. Nelder. 1989. Generalized Linear Models (2nd Edition). Chapman \& Hall, New York, New York.

Novotny, V., AND Y. BASSET. 2005. Host specificity of insect herbivores in tropical forests. Proc. R. Soc. Lond. B. Biol. Sci. 272: 1083-1090.

Novotny, V., Y. Basset, S. E. Miller, P. Drozd, and L. Cizek. 2002a. Host specialization of leaf chewing insects in a New Guinea rainforest. J. Anim. Ecol. 71: 400-412.

Novotny, V., Y. Basset, S. E. Miller, G. D. Weiblen, B. Bremer, L. Cizek, AND P. DROZD. 2002b. Low host specificity of herbivorous insects in a tropical forest. Nature 416: 841-844.

Novotny, V., P. Drozd, S. E. Miller, M. Kulfan, M. Janda, Y. Basset, and G. D. Weiblen. 2006. Why are there so many species of herbivorous insects in tropical rainforests? Science 313: 1115-1118.

Novotny, V., S. E. Miller, J. Hulcr, R. A. I. Drew, Y. Basset, M. Janda, G. P. Setliff, K. Darrow, A. J. A. Stewart, J. Auga, B. Isua, K. Molem, M. Manumbor, E. Tamtiai, M. Mogia, and G. D. Weiblen. 2007. Low beta diversity of herbivorous insects in tropical forests. Nature 448: 692-697.

Novotny, V., S. E. Miller, J. Leps, Y. Basset, D. Bito, M. Janda, J. Hulcr, K. Damas, and G. D. Weiblen. 2004. No tree an island: The plant-cater- pillar food web of a secondary rain forest in New Guinea. Ecol. Lett. 7: $1090-1100$.

ØDEGAARD, F. 2000. How many species of arthropods? Erwin's estimate revised. Biol. J. Linn. Soc. 71: 583-597.

Ødegaard, F., O. H. Diserud, and . K. Østbye. 2005. The importance of plant relatedness for host utilization among phytophagous insects. Ecol. Lett. 8: 612-617.

Oliveira-Filho, A. T., AND J. A. Ratter. 2002. Vegetation physiognomies and woody flora of the Cerrado Biome. In P. S. Oliveira and R. J. Marquis (Eds.). The cerrados of Brazil, pp. 91-120. Columbia University Press, New York, New York.

PRICE, P. 2002. Resource-driven terrestrial interaction webs. Ecol. Res. 17: 241-247.

R Development Core Team. 2006. R: A language and environment for statistical computing. R Foundation for Statistical Computing, Vienna, Austria, ISBN 3-900051-07-0.

SAno, S. M., S. P. Almeida, And J. F. Ribeiro. 2008. Cerrado: Ecologia e Flora, vol 2. Embrapa, Bras í lia, Brazil.

Stevens, P. F. 2008. Angiosperm phylogeny website. Version 9. Available at http://www.mobot.org/MOBOT/research/APweb/ (accessed 15 September 2009).

Strong, D. R. JR., J. H. Lawton, and T. R. E. Southwood. 1984. Insects on plants: Community patterns and mechanisms. Blackwell, Oxford, UK.

Tamura, K., M. Nei, and S. Kumar. 2004. Prospects for inferring very large phylogenies by using the neighbor-joining method. Proc. Nat. Acad. Sci. USA 101: 11030-11035.

Tamura, K., J. Dudley, M. Nei, and S. Kumar. 2007. MEGA4: Molecular evolutionary genetics analysis (MEGA) software version 4.0. Mol. Biol. Evol. 24: 1596-1599.

VeECh, J. A., AND T. O. CRIST. 2009. PARTITION: Software for hierarchical partitioning of species diversity, version 3.0. Available at http://www. users.muohio.edu/cristto/partition. htm (accessed 15 January 2010).

Weiblen, G. D., C. O. Webb, V. Novotny, Y. Basset, and S. E. Miller. 2006. Phylogenetic dispersion of host use in a tropical insect herbivore community. Ecology 87: S62-S75. 